\title{
Ultrasound as an Alternative to Conventional Marination: Acceptability and Mass Transfer
}

\author{
Leopolda González-González, ${ }^{1}$ Lorena Luna-Rodríguez, ${ }^{2}$ Luis M. Carrillo-López, \\ Alma D. Alarcón-Rojo, ${ }^{1}$ Iván García-Galicia, ${ }^{1}$ and Raúl Reyes-Villagrana ${ }^{2}$ \\ ${ }^{1}$ Facultad de Zootecnia y Ecología, Universidad Autónoma de Chihuahua, Periférico Francisco R. Almada Km. 1, \\ 31453 Chihuahua, CHIH, Mexico \\ ${ }^{2}$ Facultad de Zootecnia y Ecología, CONACYT-Universidad Autónoma de Chihuahua, Periférico Francisco R. Almada Km. 1, \\ 31453 Chihuahua, CHIH, Mexico
}

Correspondence should be addressed to Luis M. Carrillo-López; lmcarrillo@uach.mx

Received 5 September 2016; Revised 29 November 2016; Accepted 5 January 2017; Published 12 February 2017

Academic Editor: Jordi Rovira

Copyright (C) 2017 Leopolda González-González et al. This is an open access article distributed under the Creative Commons Attribution License, which permits unrestricted use, distribution, and reproduction in any medium, provided the original work is properly cited.

In this study, the effects of ultrasound- (US-) assisted beef marination on consumer perception and the homogeneity of the solute and mass transfer were evaluated. Marinated and US-treated meat samples $\left(40 \mathrm{kHz}, 11 \mathrm{~W} / \mathrm{cm}^{2}\right.$ for 20, 40, and $60 \mathrm{~min}$, and storing at $4^{\circ} \mathrm{C}$ for $7 \mathrm{~d}$ ) were evaluated by a group of consumers using a structured 9-point hedonic scale of satisfaction. The preferences were analyzed with XLSTAT-Sensory ${ }^{\circledR}$ software. The analysis was performed in conjunction with an energy-dispersive X-ray spectroscopic study to evaluate the sodium transference. The perception analysis indicated that the use of US-assisted marination did not increase the beef acceptability. The sonicated samples showed a more homogeneous distribution of sodium. However, traditional marination (TM) stored for $7 \mathrm{~d}$ resulted in greater mass transfer than the US-assisted marination without storage.

\section{Introduction}

Marination is a process by which an aqueous or oily solution containing different ingredients and/or additives (such as salts, polyphosphates, flavorings, and proteins) is incorporated in meat. Marination is performed on any type of meat muscle (pork, beef, chicken, turkey, and lamb) [1]. Three methods are used to produce marinated products, namely, immersion, injection, and massaging [2], with the aim of increasing the yield, improving the sensory properties, and providing tenderness [3]. One function of marination is to increase the water retention capacity in myofibrillar tissue to produce a positive effect on meat juiciness and texture [4].

However, the injection of brines containing sodium chloride, calcium chloride, polyphosphates, and acids affects the taste of meat [5]. In addition, tenderizing by mechanical methods causes mechanical breakdown, which affects the texture and appearance of meat [6]. Therefore, ultrasound(US-) assisted marination technology is considered an alternative to the traditional marinating process. Moreover,
US-assisted extraction in food processing has great potential as an emergent and innovative technology, because it is considered a "green" extraction method [7]. Advantages of this technique are the reduced extraction and processing time, reduction of solvents and energy used, and decrease of $\mathrm{CO}_{2}$ emissions.

Acoustic waves applied to solid-liquid systems increase the rate of mass transfer [8-10] by physically breaking down tissues, which creates microchannels and produces changes in the concentration gradients and the diffusion coefficients $[7,8]$. Studies have reported improved distribution of solutes [11] and changes in water retention capacity, resulting in less water loss [10], while conserving food sensory properties [12]. Classic extraction methods for products and metabolites such as oils, aromatic molecules (monoterpenoids in essential oils), chlorophylls, carotenoids, phenolic compounds, alkaloids, and antioxidants in food and natural products include maceration. US-assisted extraction reduces particle size and increases surface area, allowing for greater mass transfer and an increased extraction speed and performance $[13,14]$, 
TABLE 1: Description of treatments.

\begin{tabular}{lccc}
\hline Treatment & $\begin{array}{c}\text { Marinated } \\
\text { type }\end{array}$ & $\begin{array}{c}\text { Marinated } \\
\text { time }(\mathrm{min})\end{array}$ & $\begin{array}{c}\text { Storage at } \\
4^{\circ} \mathrm{C}(\mathrm{d})\end{array}$ \\
\hline T1 & Ultrasound & 60 & 7 \\
T2 & Ultrasound & 40 & 7 \\
T3 & Ultrasound & 20 & 7 \\
T4 & Conventional & 60 & 7 \\
T5 & Conventional & 40 & 7 \\
T6 & Conventional & 20 & 7 \\
T7 & Ultrasound & 60 & 0 \\
T8 & Ultrasound & 40 & 0 \\
T9 & Ultrasound & 20 & 0 \\
T10 & Conventional & 60 & 0 \\
T11 & Conventional & 40 & 0 \\
T12 & Conventional & 20 & 0 \\
\hline
\end{tabular}

which is similar to nanoparticles at the nanometric level becoming more reactive when particle size is reduced and surface area is increased [15].

The aim of this study was to evaluate the effect of USassisted beef marination on consumer perception and the relation of US to the homogeneity of the solute and mass transfer in the system.

\section{Materials and Methods}

2.1. Origin and Features of the Samples. Samples of bovine muscle (Longissimus dorsi) were acquired from Hereford bovine (live weight $450 \mathrm{~kg}, 24 \mathrm{~h}$ postmortem) from large meat producers. Samples were acquired at $-12^{\circ} \mathrm{C}$ and partially thawed to $4^{\circ} \mathrm{C}$ within $24 \mathrm{~h}$. Bone, fat, and connective tissue were removed. The experimental pieces were $2 \times 2 \times 2.5 \mathrm{~cm}$ $(20 \mathrm{~g})$. Samples were randomly assigned to one of 12 treatments (Table 1). In total, 36 muscle portions ( $20 \mathrm{~g}$ ) were used (three repetitions/treatment). After ultrasonication, samples were stored at $4^{\circ} \mathrm{C}$ and evaluated at 0 and $7 \mathrm{~d}$. pH determination (Sentron ${ }^{\circledR} 1001$ ) was conducted before sonication and after $7 \mathrm{~d}$ of storage.

2.2. Preparation of the Brine. A commercial brine solution was prepared for marination of meat ( $\mathrm{pH} 4.8)$. To produce the brine, seasoning $(20 \mathrm{~g})$ containing $2 \%$ sodium chloride, $1 \%$ monosodium glutamate, $31 \%$ garlic, $22 \%$ onion, $40 \%$ black pepper, $0.99 \%$ dextrose, $2 \%$ citric acid, $1 \%$ silicon dioxide, and $0.01 \%$ yellow 5 (tartrazine) was dissolved in $1000 \mathrm{~mL}$ of water.

2.3. Application of US and Description of Treatments. The samples were placed in polypropylene bags, $10 \mathrm{~mL}$ of brine was added per $20 \mathrm{~g}$ of meat, and the bags were then vacuumpacked. Sample sonication was performed in a US bath $(15 \times$ $15 \times 10 \mathrm{~cm}$ ), with a total capacity of $2.25 \mathrm{~L}$. The total amount of water used for sonication was $562.5 \mathrm{~mL}$ (Figure 1). US treatment was performed (Branson ${ }^{\circledR}$ 1510R-MTH, USA) at a frequency of $40 \mathrm{kHz}$ and a power of $11 \mathrm{~W} / \mathrm{cm}^{2}$. Once the samples were placed in the US bath, they were sonicated by applying half of the assigned time to each side, that is, 10, 20,

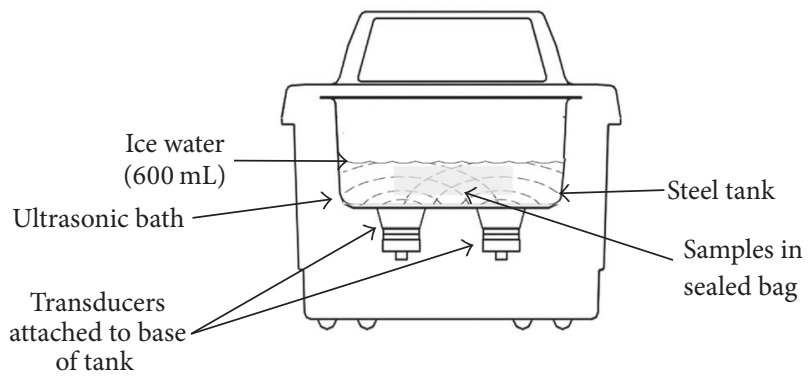

FIgURE 1: Schematic diagram of the experimental setup.

or $30 \mathrm{~min}$ on each side. The total times set for the marination were thus 20,40 , and $60 \mathrm{~min}$ (Table 1). The bath temperature was maintained constant at $4^{\circ} \mathrm{C}$ during the US application. Ice cubes were added to the bath to keep a constant temperature and water temperature was monitored with a thermocouple. Samples were placed in the bath individually and distilled water was not replaced after every sample. After sonication, vacuum bags were opened to remove excess brine, keeping approximately $3 \mathrm{~mL}$ inside with the meat, and were subsequently vacuum-repacked. Traditionally marinated (immersion) meat was also vacuum-repacked with only $3 \mathrm{~mL}$ of brine.

2.4. Measurement of the Effective Power of the US. The effective power introduced to the system by the US was measured using the calorimetric technique described by $\mathrm{M}$. A. Margulis and I. M. Margulis [16]. The method was applied to estimate the power of the acoustic wave transmitted to a solution of distilled water and dissipated as heat through the following steps. US was applied to an established volume of the solution while the temperature change of the sonicated fluid was recorded at short time intervals for $180 \mathrm{~s}$. The value of $\mathrm{d} T / \mathrm{d} t$ was estimated from the graph of temperature as a function of time. The power of the US transmitted to the fluid was obtained from the equation $P=m \times C p \times \mathrm{d} T / \mathrm{d} t$, where $P$ is the power of the ultrasound (W), $m$ is the mass of the fluid undergoing US (kg), $C p$ is the calorific capacity of the fluid at constant pressure $(\mathrm{J} / \mathrm{g} \mathrm{K})$, and $\mathrm{d} T / \mathrm{d} t$ is the slope at the origin of the curve $\left({ }^{\circ} \mathrm{C} / \mathrm{s}\right)$. The effective power of the US (acoustic intensity) is expressed in watts per unit area of the emitting surface $\left(\mathrm{W} / \mathrm{cm}^{2}\right)$ [17]. The US bath surface was used as a reference (Figure 1). By the calorimetric method, the $40 \mathrm{kHz}$ potency bath had a $\mathrm{d} T / \mathrm{d} t$ value of 0.0063 , which was substituted into the US potency equation given above. In the equation, water was considered to have a caloric capacity of $4.186 \mathrm{~J} / \mathrm{kg}^{\circ} \mathrm{C}$ and a dissolvent mass $(M)$ of $500 \mathrm{~g}$, resulting in a US output power of the system of $11 \mathrm{~W} / \mathrm{cm}^{2}$.

2.5. Consumer Characteristics. In total, 24 consumers aged 17-25 years were recruited. All reported that they consumed beef regularly.

2.6. Preparation of Samples for the Sensory Test. The samples were cooked in an electric skillet (West Bend ${ }^{\circledR}$, USA) at $176^{\circ} \mathrm{C}$ for $4 \mathrm{~min} 30 \mathrm{~s}$ on each side. The temperature at the 
geometrical center of the sample was $72^{\circ} \mathrm{C}$. The sample was presented to consumers at $55^{\circ} \mathrm{C}$.

2.7. Preference Test. The cooked samples were presented in groups of three to the consumers. Plastic containers were coded with three-digit numbers (table from the RAND Corporation [18]) and presented in a randomized order. The samples were evaluated by the consumers at the sensory analysis laboratory (designed according to Standard ISO 8589:2007 [19]) with individual booths illuminated by white lighting and at a controlled ambient temperature $\left(24^{\circ} \mathrm{C}\right)$. Consumers were provided with water for oral cleaning before the evaluation of each sample (Peachey et al., 2002).

General acceptability was determined by a scored test with a structured 9-point hedonic scale of satisfaction (1, "I dislike it a lot," to 9, "I like it a lot") and an unstructured pleasantness scale of $10 \mathrm{~cm}$ with anchors "little" on the left and "a lot" on the right, with a midpoint. The evaluated sensory properties were tenderness ("tough" to "very tender"), juiciness ("dry" to "very juicy"), taste ("weak taste" to "very pronounced taste"), and smell ("weak smell" to "pronounced smell”) [20].

2.8. Scanning Electron Microscopy. Four representative treatments were chosen for the study of the mass transfer and the semiquantitative analysis of sodium. The treatments were as follows: T1 $=60 \mathrm{~min} \mathrm{US,} 7 \mathrm{~d}$; T4 $=60 \mathrm{~min} \mathrm{MT,} 7 \mathrm{~d}$; T7 = $60 \mathrm{~min}$ US, $0 \mathrm{~d}$; and T10 $=60 \mathrm{~min} \mathrm{MT}, 0 \mathrm{~d}$. Samples measuring $0.5 \times 0.5 \times 0.5 \mathrm{~cm}^{3}$ were cut under a stereoscope (Carl Zeiss ${ }^{\circledR}$ ) and placed in $2.5 \%$ glutaraldehyde with Sorensen's phosphate buffer at $\mathrm{pH} 7.2$ for $4 \mathrm{~h}$, during periods of 5 min vacuum during the first hour of fixing. The samples were rinsed twice in Sorensen's phosphate buffer at $\mathrm{pH} 7.0$ for $10 \mathrm{~min}$. The samples were then dehydrated with an ethanol series starting at 30\% and increasing to $100 \%$ for $45 \mathrm{~min}$. The samples were then dried to the critical point with $\mathrm{CO}_{2}$ (Tousimis Samdri ${ }^{\circledR} 780 \mathrm{~A}$ ) and coated with gold for $10 \mathrm{~min}$ in an ionizer (Jeol Fine Coat Ion Sputter JFC-1100) for observation in a scanning electron microscope (JEOL JSM-6390) operated at $20 \mathrm{kV}$. The resulting data were mapped by the weight of sodium in the samples.

2.9. Statistical Analysis. The Friedman test, based on medians, with pairwise multiple comparisons using the Nemenyi test was used to analyze the effect of the US treatment on consumer perception. An agglomerative hierarchical clustering (AHC) with type proximity of similarity and Pearson's correlation coefficient with the simple linkage method were performed. For the study of preferences, a clustering of consumers was performed to create classes for the global appreciation variable associated with the four properties evaluated in the sensory test. That is, a hierarchical ascendant classification (HAC) and a principal component analysis (PCA) of the sensory properties were used to construct the external preference mapping (EPM) quadratic model. The software XLSTAT-Sensory version 2015.6.01 (Addinsoft) was used. Semiquantitative analysis of variance (ANOVA) with a mean comparison test (Tukey, $\alpha=0.05$ ) was performed using the SAS System ${ }^{\circledR} 9$ statistical package to analyze the solute distribution.
TABLE 2: Content of sodium in beef samples (longissimus dorsi) marinated with/without ultrasound and with/without storage.

\begin{tabular}{lc}
\hline Treatment & Sodium (\% in weight) \\
\hline 60 min MT, 7 d & $1.42^{\mathrm{b}}$ \\
60 min MT, 0 d & $0.64^{\mathrm{c}}$ \\
60 min US, 7 d & $1.65^{\mathrm{a}}$ \\
60 min US, 0 d & $1.18^{\mathrm{b}}$ \\
\hline
\end{tabular}

MT, marinated traditionally; US, ultrasound; d, storage days at $4^{\circ} \mathrm{C}$. The content of sodium is the average of three experiments. Means in a column without a common superscript letter differ $(P<0.05)$.

\section{Results and Discussion}

3.1. Semiquantitative Analysis and Solute Distribution. The content of sodium in beef samples showed a statistically significant difference $(P<0.0001)$ between treatments (Table 2$)$. The beef marinated via US had a larger percentage of sodium by weight than the traditionally marinated beef. In addition, the meat stored for $7 \mathrm{~d}$ showed more sodium transfer than the meat without storage, regardless of whether marination was traditional or US-assisted. Cárcel et al. [21] studied the effects of agitation with US in sirloin meat cuts and found a larger $(0.28 \pm 0.06 \mathrm{~kg} \mathrm{NaCl} / \mathrm{kg}$ initial dry matter $)$ sodium chloride content in samples with US than in those without US $(0.2 \pm 0.06 \mathrm{~kg} \mathrm{NaCl} / \mathrm{kg}$ initial dry matter $)$. They found that the sodium chloride gain in US experiments depended on the applied intensity. When the US intensity was less than $29.2 \mathrm{~W} / \mathrm{cm}^{2}$, the sodium chloride content in the US-treated meat was the same as that in the untreated meat. Above this intensity, the sodium chloride content of the sample increased proportionally to the applied intensity [21]. In contrast, in the present study, the US intensity was $11 \mathrm{~W} / \mathrm{cm}^{2}$, and a positive effect in samples with US was found. The results showed more sodium in samples with US than in samples with traditional marination only.

The results in Table 2 were confirmed by energy-dispersive X-ray spectroscopy mapping (Figure 2), where more sodium was shown distributed in the samples with US than in those traditionally marinated. However, there was more sodium distributed in the samples with traditional marination at $60 \mathrm{~min}$ and stored for $7 \mathrm{~d}$ than in those with US but without storage, showing that storage has a significant effect on mass transfer. The homogeneity and heterogeneity of the sodium distribution in the mass of the sample should be assessed. The US-assisted samples showed a more homogeneous sodium distribution, which is an advantage in marinated products because the brine produces the same flavor and water retention throughout the sample, leading to better acceptability of the product. However, the homogeneity of the brine in meat is imperceptible because of the size of the sample that is consumed in one mouthful; factors such as the percentage by weight of the salts are more useful for product acceptability. The samples treated with MT and $7 \mathrm{~d}$ of storage had more sodium, measured in percentage by weight, than the samples marinated via US but without storage. The sensory analysis described below shows higher consumer 


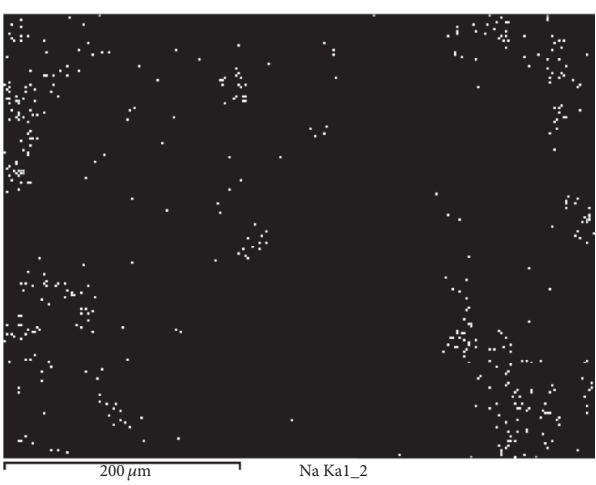

(a)

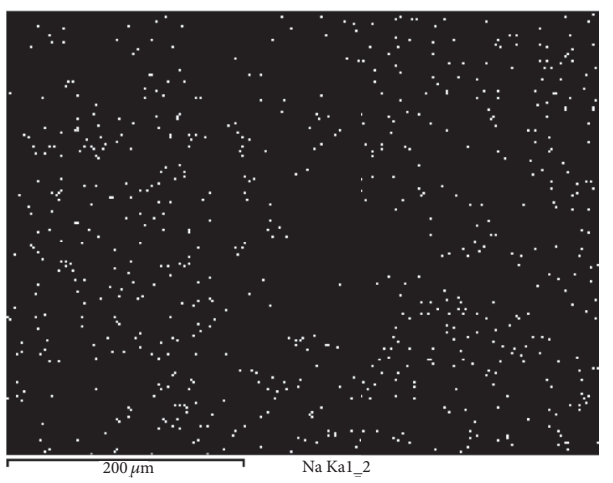

(c)

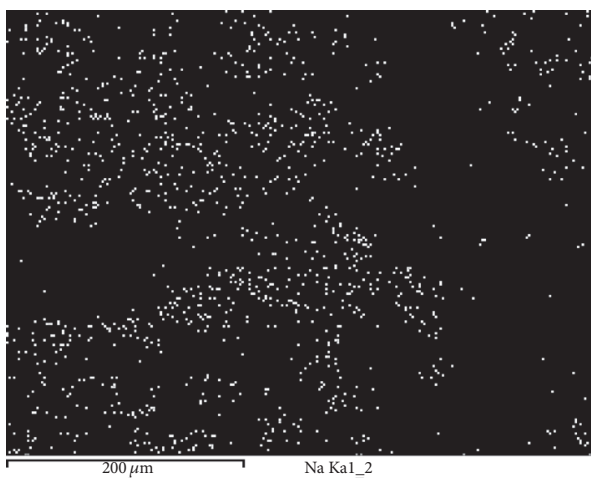

(b)

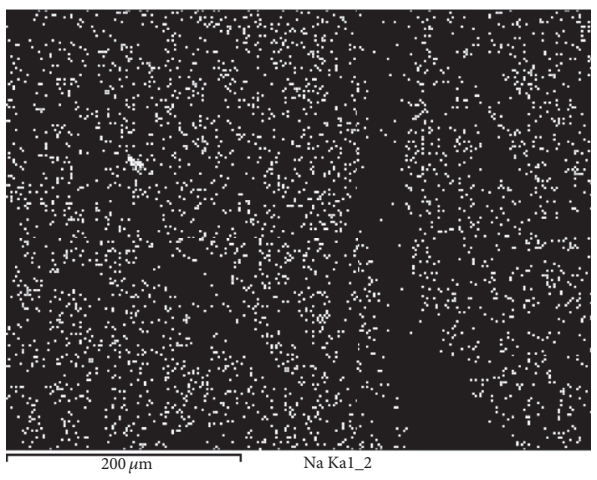

(d)

FIGURE 2: Distribution of sodium in beef samples (longissimus dorsi). (a) Marinated traditionally for 60 min without storage. (b) Marinated traditionally for $60 \mathrm{~min}$ and storage for 7 days. (c) Marinated using ultrasound for 60 min without storage. (d) Marinated using ultrasound for $60 \mathrm{~min}$ and storage for 7 days.

acceptability of the traditionally marinated samples stored for $7 \mathrm{~d}$ than the US-treated samples without storage.

Leal-Ramos et al. [9] showed that US increased the quantity of dye inside chicken meat samples by 6 and 13\% after 15 and $30 \mathrm{~min}$, respectively. This effect was much more pronounced in halal meat, which showed a $60 \%$ increase in dye absorption during the same periods. High US intensity produces multiple effects, such as increases in pressure, currents, and cavitation collapses, resulting in the formation of instabilities at the interface. This activity then affects the mass transfer processes, leading to changes in concentration gradients, diffusion coefficients, and/or boundary layers. The heating produced by the absorption of US energy (the thermoacoustic effect) affects mass diffusion. The material structure also influences the effects of the US. For example, apples are porous fruits whose pores are partially filled with air, while cheese pores are completely filled with liquid [22]. The sponge effect produced by US forces the air trapped in the pores to exit, and the marinated solution enters the pores; positive and negative pressures occur with the same frequency as US is applied. The entry of the solution to the food matrix produces an increase of solutes in US-assisted marination via a mechanism other than diffusion (LealRamos et al., 2010). The proportion of air in the pores of cheese is lower than that of an apple, and thus, the influence of compression and expansion is less important. Because there are no large pores in meat, mass transfer is more difficult. The apple is a better conductor of US vibrations because of its rigid structure, while cheese has a rubbery structure that more easily absorbs US waves. However, the absence of air pores in meat could lead to a limited effect of US.

US-assisted extraction is a technology that is cheap, efficient, and easy to operate. Its advantages can be attributed to the acoustic cavitations produced on solvents, achieving a higher penetration of solvents in the sample matrix. In addition, cavitation increases the contact surface between solid and liquid phases. As a result, solutes are rapidly distributed [23]. In the present research, the marination process was optimized by a higher gain of weight (\%) and a more homogeneous distribution of $\mathrm{Na}$ inside the $\mathrm{m}$. Longissimus dorsi, achieving an increase of $84.73 \%$ of sodium immediately after sonication $(0 \mathrm{~d})$ and a gain of $16.19 \%$ in muscle stored for $7 \mathrm{~d}$. These results strongly suggest that solute migration continues slowly during storage when meat is traditionally marinated (immersion). Hence, high-potency US may represent an efficient and environmentally friendly technology that enhances a fast migration of solutes during marination; therefore this technology could have useful industrial applications.

3.2. $p H$ Determination. The brine had a $\mathrm{pH}$ of 4.8 , an acid profile probably due to the citric acid component. The initial $\mathrm{pH}$ of the samples before any treatment was 5.8. However, the 
TABLE 3: Multiple comparisons of beef samples (longissimus dorsi).

\begin{tabular}{lcc}
\hline Samples & Summation of ranges & Means of ranges \\
\hline 60 min US, 0 d & 114.000 & $4.750^{\mathrm{b}}$ \\
40 min MT, 0 d & 116.000 & $4.833^{\mathrm{b}}$ \\
40 min US, 0 d & 122.000 & $5.083^{\mathrm{b}}$ \\
20 min US, 0 d & 123.500 & $5.146^{\mathrm{b}}$ \\
40 min MT, 7 d & 140.000 & $5.833^{\mathrm{b}}$ \\
$60 \min$ MT, 0 d & 154.000 & $6.417^{\mathrm{a}, \mathrm{b}}$ \\
$20 \min$ MT, 7 d & 163.500 & $6.813^{\mathrm{a}, \mathrm{b}}$ \\
$20 \min$ MT, 0 d & 170.000 & $7.083^{\mathrm{a}, \mathrm{b}}$ \\
$40 \min$ US, 7 d & 175.000 & $7.292^{\mathrm{a}, \mathrm{b}}$ \\
$20 \min$ US, 7 d & 179.500 & $7.479^{\mathrm{a}, \mathrm{b}}$ \\
60 min US, 7 d & 190.500 & $7.938^{\mathrm{a}, \mathrm{b}}$ \\
$60 \min$ MT, 7 d & 224.000 & $9.333^{\mathrm{a}}$ \\
\hline
\end{tabular}

MT, marinated traditionally; US, ultrasound; d, storage days at $4^{\circ} \mathrm{C}$. Significance level is 0.05 . Values in columns with different letters are statistically different $(P<0.05)$.

$\mathrm{pH}$ of both traditionally marinated and sonicated samples at $7 \mathrm{~d}$ after storage was 6.2 , due to sodium salt addition during the marination process. There was a slight difference between marinated types and times $(P=0.048$ and 0.041 , resp.). The $\mathrm{pH}$ of the samples at $0 \mathrm{~d}$ of storage increased only one and two decimals (from 5.5 to 5.9 and 6.0, traditional and USassisted, resp.). Barbut [24] reported that alkaline solutions for marinating increased water-holding capacity due to protein extraction and $\mathrm{pH}$ variation of the isoelectric point of proteins in muscle, which contributes to the dissociation of the actin-myosin complex. On the other hand, acid solutions with organic acids or their salts have been used for the same purpose [25]. In addition, Vlahova-Vangelova et al. [26] reported that alkaline marinated solutions had a stronger effect on horsemeat than acid solutions, resulting in a lower internal $\mathrm{pH}$ and a softening of the tissue.

3.3. US Effects on Consumer Perception. The means of the ranges (Table 3 ) for the levels of preference indicate that there were significant differences $(P<0.0001)$ between treatments. In addition, categorization clustered the samples by similarity in four groups (Figure 3). According to the indicated interclass variances, the groups were homogeneous (Table 4 ). The differences in perception between the US-treated meat and the traditionally marinated meat are also shown.

3.4. Preferences of Consumers of Ultrasonicated Meat. The data variability of the results mapped in Figure 4 is $95.02 \%$, illustrating that the consumer preferences varied according to US treatment. The four sensory properties evaluated were associated with the first principal component (F1).

The treatments with the greatest acceptance were as follows: T1 60 min US, 7 d; T4 60 min MT, 7 d; T6 20 min MT, $7 \mathrm{~d}$; and T10 $60 \mathrm{~min}$ MT, $0 \mathrm{~d}$. These treatments had positive values for both principal components (Figure 4). The consumer preference associated with the four attributes increased as it moved away in the direction indicated by the
TABLE 4: Results per class and grouping of beef samples (longissimus dorsi) marinated traditionally or using ultrasound.

\begin{tabular}{|c|c|c|c|}
\hline Class & Samples per class & Interclass variance & Treatment \\
\hline \multirow{5}{*}{1} & \multirow{5}{*}{5} & \multirow{5}{*}{58.600} & $60 \mathrm{~min}$ US, $0 \mathrm{~d}$ \\
\hline & & & $40 \mathrm{~min}$ US, $0 \mathrm{~d}$ \\
\hline & & & $20 \mathrm{~min}$ US, $0 \mathrm{~d}$ \\
\hline & & & $60 \mathrm{~min}$ US, $7 \mathrm{~d}$ \\
\hline & & & $40 \min$ US, $7 \mathrm{~d}$ \\
\hline \multirow{3}{*}{2} & \multirow{3}{*}{3} & \multirow{3}{*}{45.333} & $60 \min \mathrm{MT}, 0 \mathrm{~d}$ \\
\hline & & & $40 \min \mathrm{MT}, 0 \mathrm{~d}$ \\
\hline & & & $20 \min \mathrm{MT}, 0 \mathrm{~d}$ \\
\hline \multirow{3}{*}{3} & \multirow{3}{*}{3} & \multirow{3}{*}{35.333} & $20 \min$ US, $7 \mathrm{~d}$ \\
\hline & & & $60 \min \mathrm{MT}, 7 \mathrm{~d}$ \\
\hline & & & $40 \min \mathrm{MT}, 7 \mathrm{~d}$ \\
\hline 4 & 1 & 0.000 & $20 \min \mathrm{MT}, 7 \mathrm{~d}$ \\
\hline
\end{tabular}

MT, marinated traditionally; US, ultrasound; d, storage days at $4^{\circ} \mathrm{C}$.

vector. US treatments with $0 \mathrm{~d}$ of storage were less preferred than the others.

The US waves acting on the meat surface enable the introduction of the brine from US cavitation [27], which produces microchannels close to the solid surface, triggering brine microinjection in meat samples and resulting in a net increase of sodium chloride in the meat from the brining process [8]. However, the results from the study of the perceptions of the consumer panel do not support this theory because the consumers did not show a marked preference for the US-treated meat, although the treatments with $7 \mathrm{~d}$ of storage were preferred by the consumers with respect to the evaluated properties.

Muscular tissue has lower ionic strength during the traditional marination process compared with brining, reaching equilibrium status by osmosis. This explains why there were no differences in consumer preferences between traditional marination for $60 \mathrm{~min}$ with storage and the US-assisted marination with storage.

Equilibrium status was also reported by Sánchez et al. [28], who analyzed samples of Mahón cheese when adding salt using traditional brining and US-assisted brining. Although previous measurements noted some differences, there was a uniform distribution of sodium chloride in all treatments during the ripening stage. Furthermore, Turhan et al. [29] studied the effect of US-assisted marination $(20 \mathrm{kHz}$ with 20,25 , and $30 \mathrm{~W} / \mathrm{cm}^{2}$ ) on the transport of acetic acid (4 and $8 \%)$ and salt in anchovy marinades. The authors showed that the moisture content decreased as the US intensity increased. The water solid content could also affect the perception of juiciness.

Another factor that seems to have a critical influence on consumer preferences is storage time $(7 \mathrm{~d})$. At $48 \mathrm{~h}$ postmortem, meat is still fresh, and during the storage period, proteolysis caused by calpains contributes to increased tenderness and taste. This proteolysis process can persist up to 10-14 d postmortem in beef [30]. 


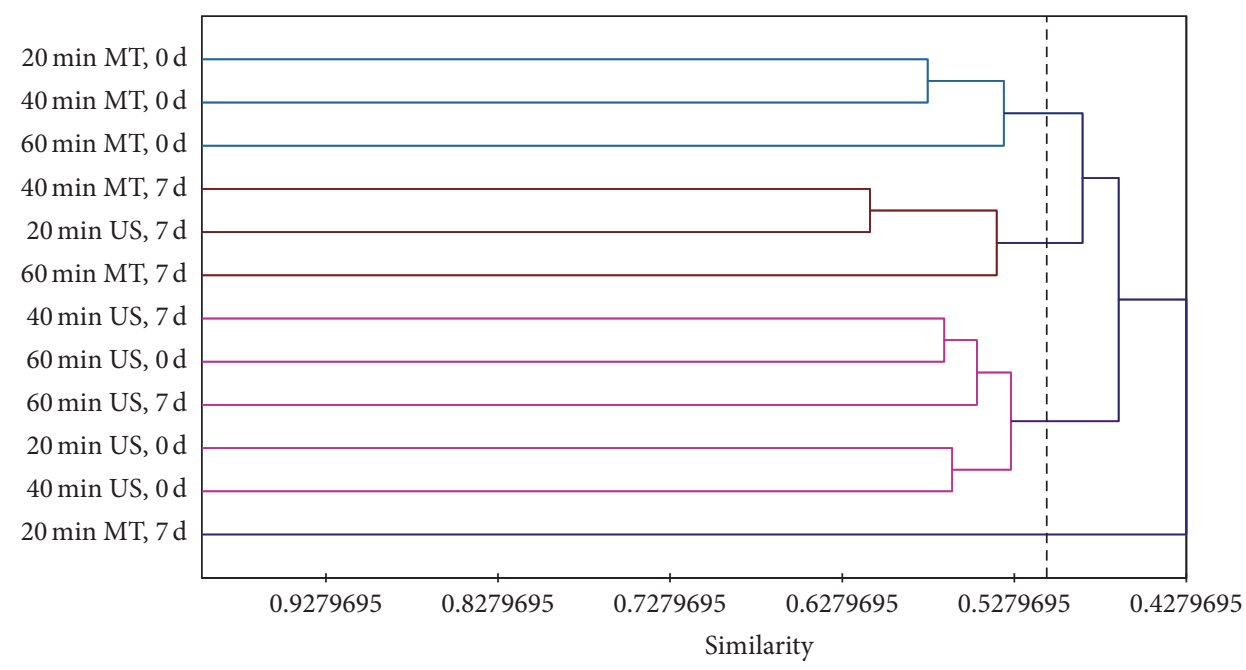

FIGURE 3: Categorization of beef samples (longissimus dorsi) using two types of marination processes. MT, marinated traditionally; US, ultrasound; d, storage days at $4^{\circ} \mathrm{C}$. The sensory test was carried out using 24 consumers. The dashed line represents truncation in homogeneous groups.

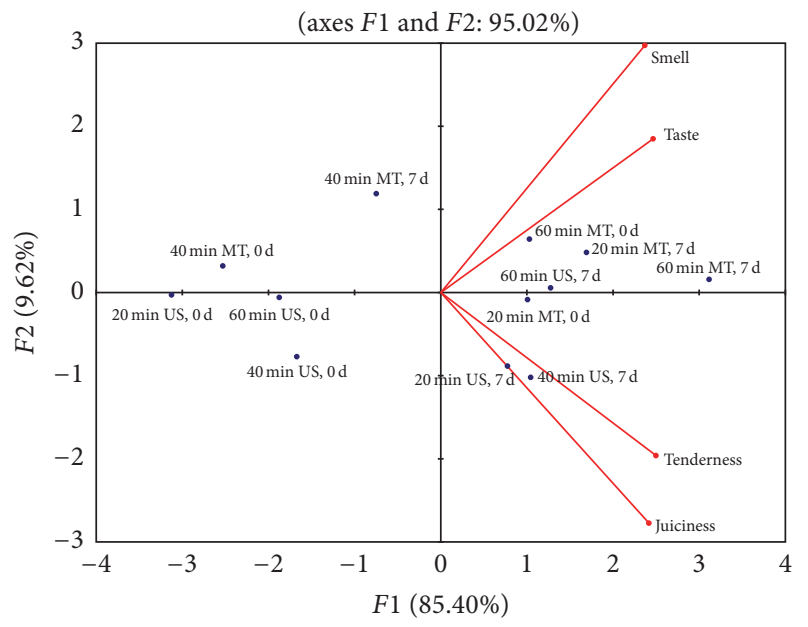

FIGURE 4: Sensory space of beef samples (longissimus dorsi) using two types of marination processes. MT, marinated traditionally; US, ultrasound; $\mathrm{d}$, storage days at $4^{\circ} \mathrm{C}$.

External preference mapping (Figure 5) showed that there were significant effects for consumers in classes 1 and $4\left(R^{2}=\right.$ 0.862 and $R^{2}=0.818$, resp.; $P<0.05$ ). The model explains the preferences for these groups of consumers. For group 1, the best treatments in order of preference were as follows: T4 60 min MT, 7 d; T5 40 min US, 7 d; T6 20 min MT, 7 d; and T1 60 min US, $7 \mathrm{~d}$. For group 2, the best treatments in order of preference were as follows: T4 $60 \mathrm{~min} \mathrm{MT,} 7 \mathrm{~d}$; T6 $20 \mathrm{~min}$ MT, 7 d; T2 40 min US, 7 d; and T1 60 min US, 7 d. For classes 2 and 3, the model used in this study could not explain the preferences.

The percentage of satisfied consumer judges (Figure 5) was $100 \%$ for the following: T1 $60 \mathrm{~min}$ US, $7 \mathrm{~d}$; T4 $60 \mathrm{~min} \mathrm{MT}$, $7 \mathrm{~d}$; and T6 $20 \mathrm{~min}$ MT, $7 \mathrm{~d}$. Treatments with $0 \mathrm{~d}$ storage with or without US obtained the lowest percentage of satisfaction $(0-20 \%)$.
Microchannels are generated inside meat samples and affect the tenderness because of cell disruption [8]. Smith [31] found that the marination method does not influence the instrumental texture. However, the percentage of satisfied judges suggests that treatments with $7 \mathrm{~d}$ of storage have the best acceptability, which infers that postmortem softening has an effect on preference. During meat maturation at $4^{\circ} \mathrm{C}$, endogenous proteolytic systems alter the architecture and integrity of the muscle cells, improving tenderness [32]; the characteristic smell of meat also originates during this process. The effect of US on preference is measured by the sensory properties; however, it is also measured by the final concentration and distribution of solutes in the meat, as explained below.

The data in Figure 4 show that principal component 1 is the primary component responsible for the variance between the treatments $(85.40 \%)$. Treatments with $7 \mathrm{~d}$ of storage tend to move toward positive values whereas treatments without storage move toward negative values. Similarly, the features caused by proteolysis (smell, taste, tenderness, and juiciness) are found in the same positive quadrants. This is consistent with the suggestion that those sensory features benefited from storage. However, for principal component 2 (9.62\%), a small but additional effect of sonication was shown in the development of tenderness and juiciness while in storage, but only at moderate times (20 and $40 \mathrm{~min}$, lower-right quadrant). In summary, Figure 5 shows that most of the clusters of preference and satisfaction are found in the lowerright quadrant, that is, the convergent point between length of storage and short-to-medium US duration.

\section{Conclusions}

The data in this study confirm that US offers a positive alternative to traditional marination techniques because the UStreated meat presented a homogeneous distribution of the brine solutes in the meat. Even though the preliminary 


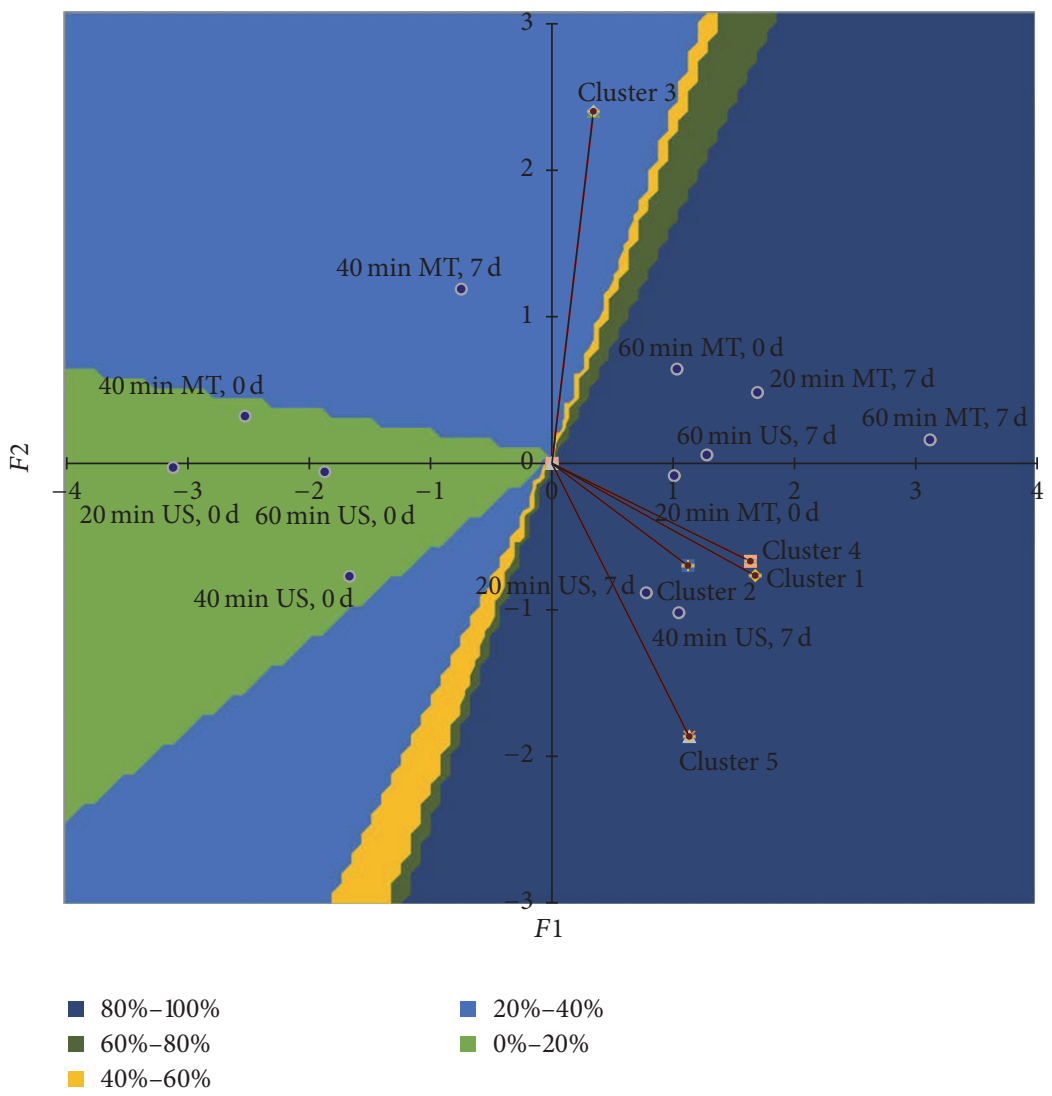

FIGURE 5: Preferences and satisfaction (\%) of beef samples (longissimus dorsi). MT, marinated traditionally; US, ultrasound; d, storage days at $4^{\circ} \mathrm{C}$; Cluster, segmentation of the consumer judges in groups of similar preferences.

perception analysis showed that the use of US-assisted marination does not increase the sensory properties of beef, a quantitative descriptive sensory analysis with a trained panel should be considered to evaluate the perception of specific properties in meat in homogeneous and heterogeneous distributions of brine. The acceptability of the marinated product depends on the largest mass transfer to the meat, not on the homogeneity and heterogeneity of the solute distribution.

\section{Competing Interests}

The authors declare that there is no conflict of interests regarding the publication of this paper.

\section{Acknowledgments}

The authors acknowledge the Electron Microscopy Unit of the "Colegio de Postgraduados (COLPOS)" (Postgraduate College of Agriculture), México, for assistance with scanning electron microscopy.

\section{References}

[1] Z. Y. Tapasco, M. D. A. Restrepo, and M. H. Suárez, "Efecto reológico de hidrocoloides sobre la salmuera de marinado de carne bovina," Biotecnología en el Sector Agropecuario y Agroindustrial, vol. 9, no. 2, pp. 23-31, 2011.
[2] C. Alvarado and S. McKee, "Marination to improve functional properties and safety of poultry meat," Journal of Applied Poultry Research, vol. 16, no. 1, pp. 113-120, 2007.

[3] L. L. Young and D. P. Smith, "Effect of vacuum on moisture absorption and retention by marinated broiler fillets," Poultry Science, vol. 83, no. 1, pp. 129-131, 2004.

[4] M. Xargayó, J. E. Lagares, D. Fernández, D. Borrell, and G. Junca, "Solution for Improving meat texture. Influence of spray injection on the organoleptica and sensory characteristics," Fleis-Chwirtschaft International, vol. 2, pp. 68-74, 2004.

[5] T. E. Lawrence, M. E. Dikeman, M. C. Hunt, C. L. Kastner, and D. E. Johnson, "Effects of enhancing beef longissimus with phosphate plus salt, or calcium lactate plus non-phosphate water binders plus rosemary extract," Meat Science, vol. 67, no. 1, pp. 129-137, 2004.

[6] L. H. Hayward, M. C. Hunt, C. L. Kastner, and D. H. Kropf, "Blade tenderization effects on beef longissimus sensory and instron textural measurements," Journal of Food Science, vol. 45, no. 4, pp. 925-935, 1980.

[7] F. Chemat, Zill-e-Huma, and M. K. Khan, "Applications of ultrasound in food technology: processing, preservation and extraction," Ultrasonics Sonochemistry, vol. 18, no. 4, pp. 813835, 2011.

[8] J. A. Cárcel, J. Benedito, J. Bon, and A. Mulet, "High intensity ultrasound effects on meat brining," Meat Science, vol. 76, no. 4, pp. 611-619, 2007.

[9] M. Y. Leal-Ramos, A. D. Alarcon-Rojo, T. J. Mason, L. Paniwnyk, and M. Alarjah, "Ultrasound-enhanced mass transfer in 
Halal compared with non-Halal chicken," Journal of the Science of Food and Agriculture, vol. 91, no. 1, pp. 130-133, 2011.

[10] I. Siró, C. Vén, C. Balla, G. Jónás, I. Zeke, and L. Friedrich, "Application of an ultrasonic assisted curing technique for improving the diffusion of sodium chloride in porcine meat," Journal of Food Engineering, vol. 91, no. 2, pp. 353-362, 2009.

[11] C. Ozuna, A. Puig, J. V. García-Pérez, A. Mulet, and J. A. Cárcel, "Influence of high intensity ultrasound application on mass transport, microstructure and textural properties of pork meat (Longissimus dorsi) brined at different $\mathrm{NaCl}$ concentrations," Journal of Food Engineering, vol. 119, no. 1, pp. 84-93, 2013.

[12] C. K. McDonnell, J. G. Lyng, J. M. Arimi, and P. Allen, "The acceleration of pork curing by power ultrasound: a pilot-scale production," Innovative Food Science and Emerging Technologies, vol. 26, pp. 191-198, 2014.

[13] K. S. Suslick and G. J. Price, "Applications of ultrasound to materials chemistry," Annual Review of Materials Science, vol. 29, pp. 295-326, 1999.

[14] K. A. Kusters, S. E. Pratsinis, S. G. Thoma, and D. M. Smith, "Ultrasonic fragmentation of agglomerate powders," Chemical Engineering Science, vol. 48, no. 24, pp. 4119-4127, 1993.

[15] L. M. Carrillo-López, R. M. Soto-Hernández, H. A. ZavaletaMancera, and A. R. Vilchis-Néstor, "Study of the performance of the organic extracts of Chenopodium ambrosioides for Ag nanoparticle synthesis," Journal of Nanomaterials, vol. 2016, Article ID 4714162, 13 pages, 2016.

[16] M. A. Margulis and I. M. Margulis, "Calorimetric method for measurement of acoustic power absorbed in a volume of a liquid," Ultrasonics Sonochemistry, vol. 10, no. 6, pp. 343-345, 2003.

[17] A. R. Jambrak, T. J. Mason, V. Lelas, L. Paniwnyk, and Z. Herceg, "Effect of ultrasound treatment on particle size and molecular weight of whey proteins," Journal of Food Engineering, vol. 121, no. 1, pp. 15-23, 2014.

[18] M. Schonlau, R. D. Fricker, and M. N. Elliot, Conducting Research Surveys via E-Mail and the Web, Rand Documents, The Rand Corporation, Santa Mónica, Calif, USA, 2002.

[19] ISO, "Sensory analysis-general guidance for the design of test rooms," International Standard 8589, International Organization for Standarization, 2007.

[20] T. M. Ngapo, L. Riendeau, C. Laberge, and J. Fortin, "Marbling and ageing - Part 2. Consumer perception of sensory quality," Food Research International, vol. 51, no. 2, pp. 985-991, 2013.

[21] J. Cárcel, A. J. Benedito, A. Mulet, and E. Riera, "Mass transfer effects during meat ultrasonic brining," in Proceedings of the World Congress of Ultrasonics, vol. 1, pp. 431-434, 2003.

[22] A. Mulet, J. J. Carcel, C. Benedito, C. Rossello, and S. Simal, "Ultrasonic mass transfer enhancement in food processing," in Transport Phenomena in Food Processing, J. Welti-Chanes and J. Velez-Ruiz, Eds., vol. 18, chapter 8, pp. 265-278, CRC Press, Boca Raton, Fla, USA, 2003.

[23] Z. Lianfu and L. Zelong, "Optimization and comparison of ultrasound/microwave assisted extraction (UMAE) and ultrasonic assisted extraction (UAE) of lycopene from tomatoes," Ultrasonics Sonochemistry, vol. 15, no. 5, pp. 731-737, 2008.

[24] S. Barbut, "Poultry products-formulation and gelation. Poultry products processing," in An Industry Guide, pp. 249-288, CRC Press, New York, NY, USA, 2002.

[25] J. B. Hinkle, Acid marination for tenderness enhancement of beef bottom round, Theses and Dissertations in Animal Science, Paper 12, University of Nebraska-Lincoln, European Food Research and Technology, 2010.
[26] D. B. Vlahova-Vangelova, S. Abjanova, and S. G. Dragoev, "Influence of the marinating type on the morphological and sensory properties of horse meat," Acta Scientiarum Polonorum, Technologia Alimentaria, vol. 13, no. 4, pp. 403-411, 2014.

[27] T. J. Mason and J. P. Lorimer, Applied Sonochemistry. The Uses of Power Ultrasound in Chemistry and Processing, Wiley-VCH, Weinheim, Germany, 2002.

[28] E. S. Sánchez, S. Simal, A. Femenia, and C. Rosselló, "Effect of acoustic brining on the transport of sodium chloride and water in Mahon cheese," European Food Research and Technology, vol. 212, no. 1, pp. 39-43, 2000.

[29] S. Turhan, F. T. Saricaoglu, and F. Oz, "The effect of ultrasonic marinating on the transport of acetic acid and salt in anchovy marinades," Food Science and Technology Research, vol. 19, no. 5, pp. 849-853, 2013.

[30] M. Koohmaraie, S. C. Seidemann, J. E. Schollmeyer, T. R. Dutson, and J. D. Crouse, "Effect of post-mortem storage on $\mathrm{Ca}^{++}$dependent proteases, their inhibitor and myofibril fragmentation," Meat Science, vol. 19, no. 3, pp. 187-196, 1987.

[31] D. P. Smith, "Effect of ultrasonic marination on broiler breast meat quality and Salmonella contamination," International Journal of Poultry Science, vol. 10, no. 10, pp. 757-759, 2011.

[32] T. Lian, L. Wang, and Y. Liu, "A new insight into the role of calpains in post-mortem meat tenderization in domestic animals: a review," Asian-Australasian Journal of Animal Sciences, vol. 26, no. 3, pp. 443-454, 2013. 

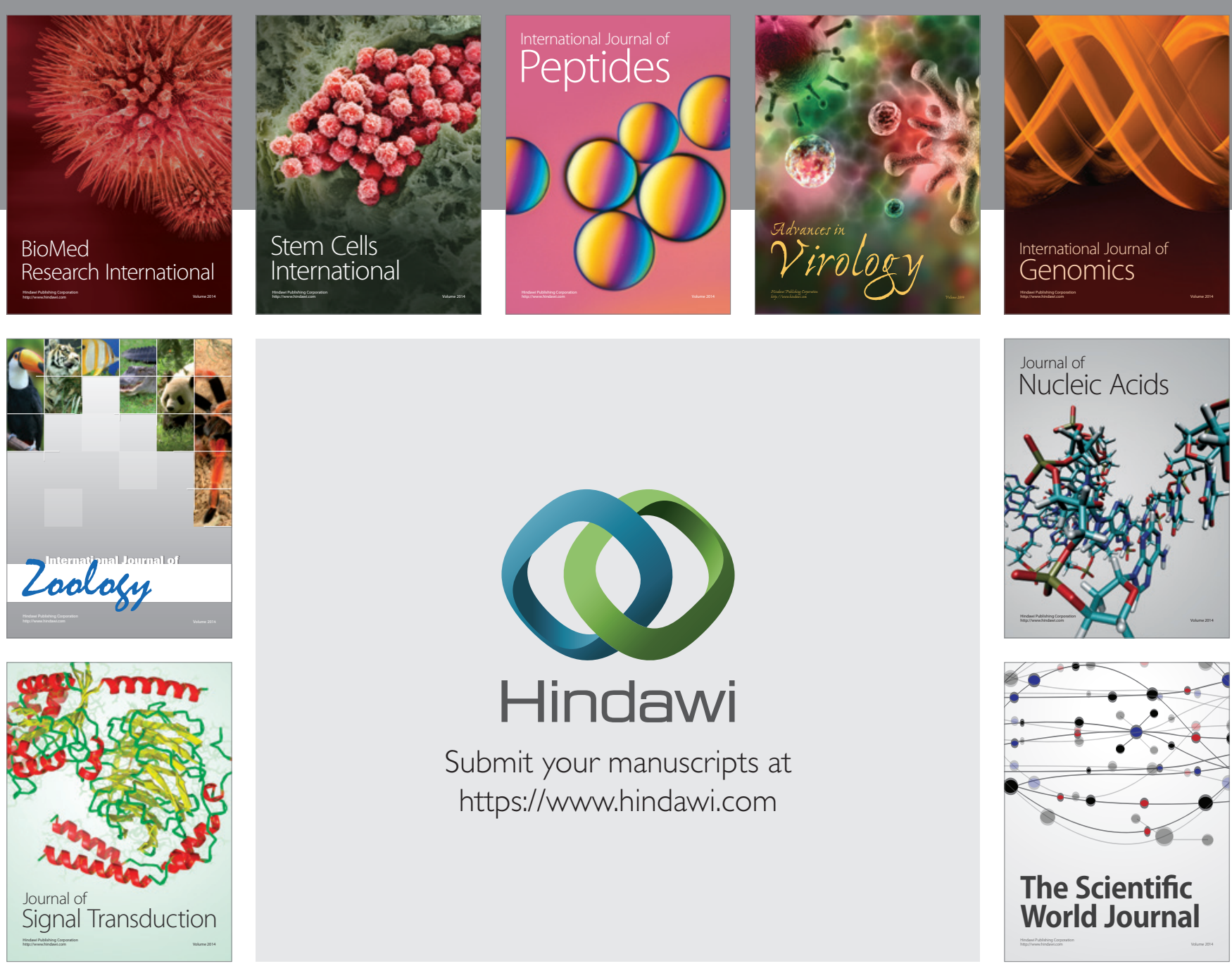

Submit your manuscripts at

https://www.hindawi.com
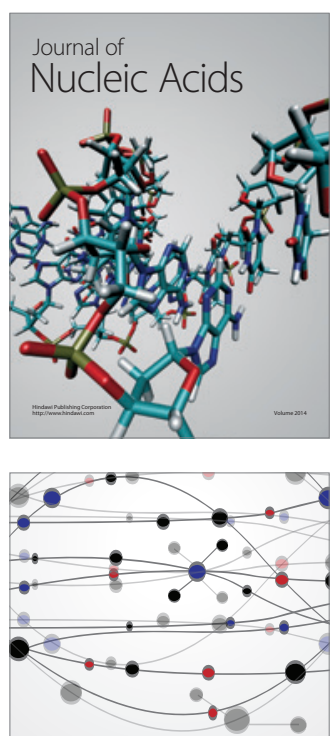

The Scientific World Journal
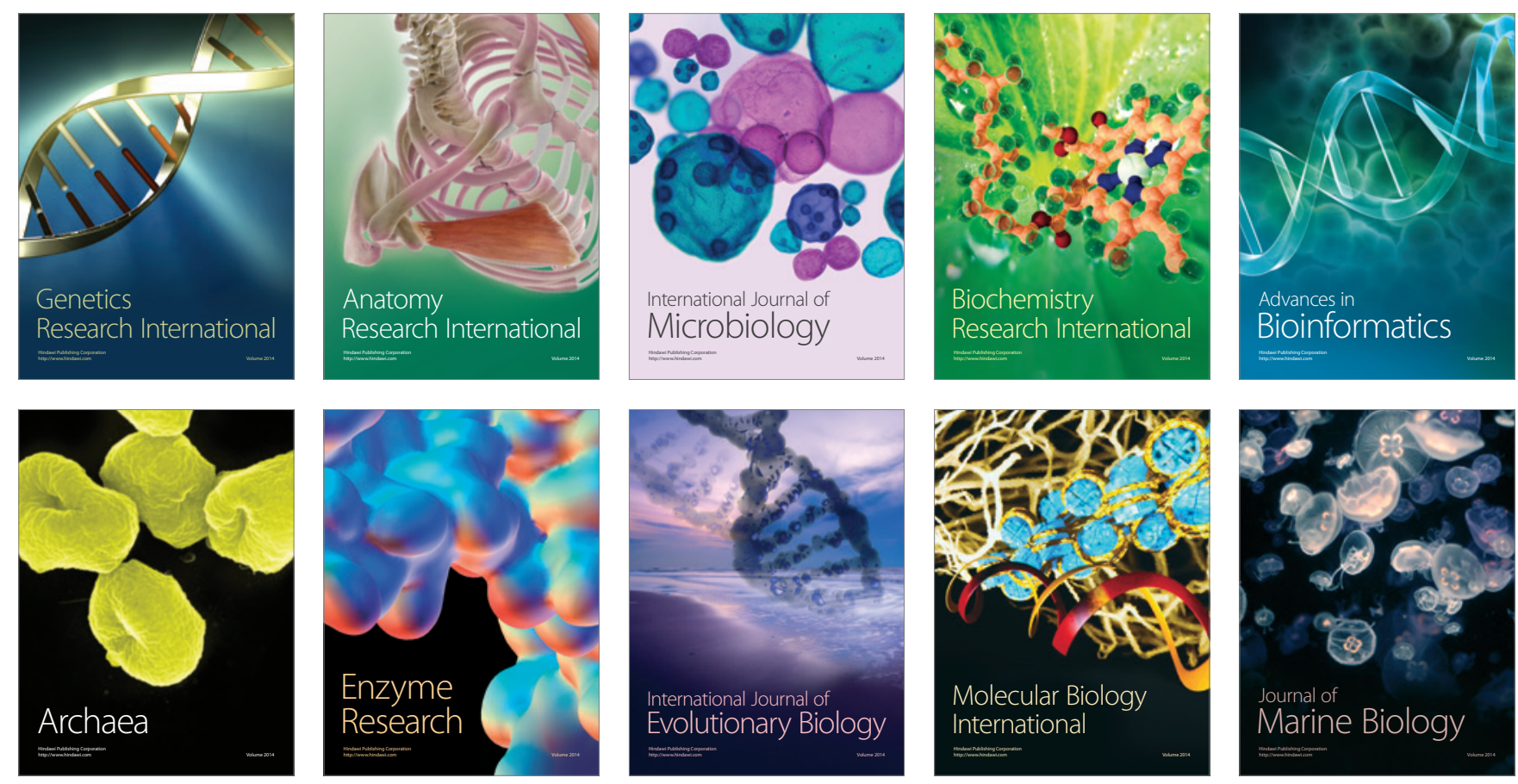